\title{
ARTICLE
}

Myelodysplastic syndrome

\section{A phase 3 randomized, placebo-controlled study assessing the efficacy and safety of epoetin- $\alpha$ in anemic patients with low-risk MDS}

\author{
Pierre Fenaux ${ }^{1}$ Valeria Santini ${ }^{2} \cdot$ Maria Antonietta Aloe Spiriti ${ }^{3} \cdot$ Aristoteles Giagounidis $^{4} \cdot$ Rudolf Schlag $^{5}$. \\ Atanas Radinoff ${ }^{6} \cdot$ Liana Gercheva-Kyuchukova $^{7}$ - Achilles Anagnostopoulos ${ }^{8} \cdot$ Esther Natalie Oliva $^{9}$. \\ Argiris Symeonidis $^{10} \cdot$ Mathilde Hunault Berger $^{11} \cdot$ Katharina S. Götze $^{12} \cdot$ Anna Potamianou $^{13} \cdot$ Hari Haralampiev $^{14}$. \\ Robert Wapenaar $^{15} \cdot$ Iordanis Milionis $^{16} \cdot$ Uwe Platzbecker $^{17}$
}

Received: 26 September 2017 / Revised: 21 December 2017 / Accepted: 14 February 2018 / Published online: 30 March 2018

(c) The Author(s) 2018. This article is published with open access

\begin{abstract}
Erythropoiesis-stimulating agents are first choice for treating anemia in low-risk MDS. This double-blind, placebo-controlled study assessed the efficacy and safety of epoetin- $\alpha$ in IPSS low- or intermediate-1 risk (i.e., low-risk) MDS patients with $\mathrm{Hb} \leq 10.0 \mathrm{~g} / \mathrm{dL}$, with no or moderate RBC transfusion dependence ( $\leq 4 \mathrm{RBC}$ units/8 weeks). Patients were randomized, $2: 1$, to receive epoetin- $\alpha 450 \mathrm{IU} / \mathrm{kg} /$ week or placebo for 24 weeks, followed by treatment extension in responders. The primary endpoint was erythroid response (ER) through Week 24. Dose adjustments were driven by weekly Hb-levels and included increases, and dose reductions/discontinuation if $\mathrm{Hb}>12 \mathrm{~g} / \mathrm{dL}$. An independent Response Review Committee (RRC) blindly reviewed all responses, applying IWG-2006 criteria but also considering dose adjustments, drug interruptions and longer periods of observation.
\end{abstract}

A total of 130 patients were randomized ( 85 to epoetin- $\alpha$ and 45 to placebo). The ER by IWG-2006 criteria was $31.8 \%$ for epoetin- $\alpha$ vs $4.4 \%$ for placebo $(p<0.001)$; after RRC review, the ER was 45.9 vs $4.4 \%(p<0.001)$, respectively. Epoetin- $\alpha$ reduced $\mathrm{RBC}$ transfusions and increased the time-to-first-transfusion compared with placebo.

Thus, epoetin- $\alpha$ significantly improved anemia outcomes in low-risk MDS. IWG-2006 criteria for ER may require amendments to better apply to clinical studies.

Electronic supplementary material The online version of this article (https://doi.org/10.1038/s41375-018-0118-9) contains supplementary material, which is available to authorized users.

Pierre Fenaux

pierre.fenaux@aphp.fr

Hôpital St. Louis, Assistance Publique Hôpitaux de Paris, Université Paris Diderot, Paris, France

2 Hematology AOU Careggi, University of Florence, Florence, Italy

3 Sapienza Università di Roma, Rome, Italy

4 Marien Hospital, Düsseldorf, Germany

5 Praxisklinik Würzburg, Würzburg, Germany

6 University Hospital Sveti Ivan Rislki, Sofia, Bulgaria

7 Varna Clinic of Haematology, Varna, Bulgaria

8 George Papanicolaou Hospital, Thessaloniki, Greece

9 Grande Ospedale Metropolitano Bianchi-Melacrino-Morelli,
Calabria, Italy

10 Department of Hematology, Medical School, University of Patras, Patras, Greece

11 CHU Angers, Angers, France

12 Technische Universität München, Munich, Germany

13 EMEA Medical Affairs, Janssen-Cilag, Neuss, Germany

14 EMEA Medical Affairs, Covance CoSource on assignment with Janssen, Sofia, Bulgaria

15 Biostatistics, Janssen-Cilag BV, Breda, The Netherlands

16 EMEA Medical Affairs, Janssen-Cilag Pharmaceutical SACI, Athens, Greece

17 Medizinische Klinik und Poliklinik I, Dresden, Germany 


\section{Key points (short bulleted statements of relevant outcomes)}

- Epoetin- $\alpha$ improved erythroid response, reduced the percentage of patients requiring red blood cell transfusion and increased the time-to-first-transfusion compared with placebo

- Epoetin- $\alpha$ was well tolerated in anemic patients with low- and intermediate-1 risk MDS

\section{Introduction}

MDS are clonal myeloid disorders, characterized by ineffective hematopoiesis, leading to peripheral blood cytopenias and an increased risk of progression to acute myeloid leukemia (AML) [1]. Myelodysplastic syndromes (MDS) are classified prognostically by the International Prognostic Scoring System (IPSS). In low-risk MDS (i.e., IPSS low- or intermediate-1risk), anemia is the predominant feature, leading to red blood cell (RBC) transfusion requirement, poor quality of life (QoL), and worsening of comorbidities [2].

Until recently, lenalidomide was the only drug approved in the EU to treat anemia associated with low-risk MDS, but only in patients with $5 \mathrm{q}$ deletion; however, many studies have evaluated erythropoiesis-stimulating agents (ESAs) in all subgroups of patients with MDS [3-5]. Recombinant human erythropoietin alfa (epoetin- $\alpha$; Eprex ${ }^{\circ}$ ) stimulates proliferation of RBC precursors and inhibits their apoptosis in MDS [6]. In the EU, epoetin- $\alpha$ is indicated to treat symptomatic anemia associated with chronic renal failure, chemotherapy-treated adult cancer patients at risk of transfusion, adults in a pre-donation program to increase the yield of autologous blood, and patients prior to orthopedic surgery at risk of transfusion complications [7].

Epoetin- $\alpha$ has been used to treat anemia in low-risk MDS patients, primarily in non-randomized, single-arm studies [8-11]. A well-designed, randomized, double-blind study with sufficient size and duration was required to compare epoetin- $\alpha$ with placebo in improving anemia outcomes in patients with low-risk MDS.

We designed a phase 3 multicenter double-blind placebocontrolled study to evaluate epoetin- $\alpha$ as treatment for anemia in low-risk MDS. Evaluation of our results led us to reconsider some of the International Working group (IWG)2006 criteria for erythroid response (ER).

\section{Methods}

\section{Study design}

Adults with MDS were randomized in a 2:1 ratio to receive either epoetin- $\alpha$ or placebo, at 29 sites in six countries across
Europe. Inclusion criteria were de novo MDS according to WHO classification, and IPSS low- or intermediate-1 (lowrisk) at screening, hemoglobin $(\mathrm{Hb}) \leq 10 \mathrm{~g} / \mathrm{dL}(10.5 \mathrm{~g} / \mathrm{dL}$ in case of preceding transfusion), serum erythropoietin $<500$ $\mathrm{mU} / \mathrm{mL}$, transfusion requirement $\leq 4 \mathrm{RBC}$ units $/ 8$ weeks, ECOG performance status $\leq 2$, and adequate iron, B12 and folate levels. Exclusion criteria were therapy-related MDS, uncontrolled hypertension, prior treatment with any ESA or interventional agents, and a history of pure red cell aplasia. Randomization was stratified according to transfusion requirement (yes vs no) and serum erythropoietin levels ( $\geq 200 \mathrm{mU} / \mathrm{mL}$ vs $<200 \mathrm{mU} / \mathrm{mL}$ ).

Epoetin- $\alpha$ was administered weekly, subcutaneously at an initial dose of $450 \mathrm{IU} / \mathrm{kg}$ (up to $40,000 \mathrm{IU}$ total dose) or matching volume of placebo. $\mathrm{Hb}$ was measured weekly, either centrally or at local sites. At week 8 the dose could be increased up to $1050 \mathrm{IU} / \mathrm{kg}$ (up to $80,000 \mathrm{IU}$ total dose) or matching volume of placebo in patients not achieving an ER. If $\mathrm{Hb}$ levels increased to $>12 \mathrm{~g} / \mathrm{dL}$, or there was a rapid increase in $\mathrm{Hb}$ levels $(>2 \mathrm{~g} / \mathrm{dL}$ over any 4 -week period), treatment with epoetin- $\alpha$ was interrupted. Stepwise dose adjustments were permitted for patients not achieving ER, and dose reduction/interruption driven by weekly $\mathrm{Hb}$ regardless of ER status (Table S1). At the end of Week 24, responders could enter the double-blind extension phase through Week 48 continuing with the same dosing rules (Figure S1). Patients completing or discontinuing treatment were followed for a further 4 weeks.

\section{Endpoints}

The primary endpoint was ER through Week 24, according to IWG-2006 criteria [12]. Following difficulties in assessing response using the IWG-2006 criteria-due in particular to the per label dose adjustment of epoetin- $\alpha$-an independent response review committee (RRC) reviewed blinded data on dosing, transfusions, Hb levels and somewhat modified IWG-2006 criteria for ER as follows: (i) patients with an increase in $\mathrm{Hb}$ level by at least $1.5 \mathrm{~g} / \mathrm{dL}$ lasting less than 8 weeks due to epoetin- $\alpha$ discontinuation were considered responders if, when restarting epoetin- $\alpha$ at lower dose, $\mathrm{Hb}$ still increased by at least $1.5 \mathrm{~g} / \mathrm{dL}$, (ii) in transfused patients, the baseline $\mathrm{Hb}$ value was taken before the last transfusion preceding enrollment (rather than after), and (iii) if discrepancies were observed between local and centralized $\mathrm{Hb}$ levels, the latter should be used to evaluate response and its duration (Table S2).

Secondary endpoints included duration of ER through 48 weeks, time-to-RBC-transfusion, the number of RBC units transfused, and QoL. QoL questionnaires included the Functional Assessment of Cancer Therapy-Anemia/Fatigue (FACT-An), EuroQol 5-dimension (EQ-5D-3L). AEs were collected for patients who received $\geq 1$ dose of study 
medication. An independent data and safety monitoring committee reviewed unblinded safety and efficacy data.

\section{Open-label access study}

Patients in Bulgaria, Greece, and Germany responding to treatment with epoetin- $\alpha$ at Week 48 , and non-responders by Week 24 treated with placebo were eligible for an openlabel study, where they could receive, or continue to receive, epoetin- $\alpha$ at the end of their participation in the EPOANE3021 study. The duration was 6 months in Germany and Greece, and up to 1 year after the last patient had enrolled in Bulgaria, or until early discontinuation). Patients were given an initial dose of epoetin- $\alpha 450 \mathrm{IU} / \mathrm{kg}$ and a maximum dose of $40,000 \mathrm{IU} / \mathrm{kg}$ weekly for the first 8 weeks, after which the protocol-defined dosing schedule and modifications were applied, or continued the same dose when entering the open-label study. Patients were withdrawn from the study when treated with the maximum dose for 8 weeks without response.

\section{Statistical analysis}

Sample size was based on an expected response rate of $35 \%$ and $10 \%$ in the epoetin- $\alpha$ and placebo groups, respectively. Using a Fisher exact test with a 0.05 two-sided significance level, corrected for a $10 \%$ drop out rate, $\geq 125$ patients ( 83 epoetin- $\alpha, 42$ placebo) were required to achieve $\geq 80 \%$ power. All statistical tests were two-sided at a significance level of 0.05 . Modified intent to treat (mITT-patients with $\geq 1$ dose and one post-baseline assessment) and per protocol (PP-no major protocol deviations during the first 24 weeks) analyses were used for all efficacy analyses. For ER, Fisher's, and Cochran-Mantel-Haenszel test were used (the latter taking into account stratification factors and IPSS risk category at screening). Between-group comparisons were tested using the Fisher exact test or Wilcoxon two-sample test.

\section{Results}

\section{Patient characteristics}

Of 130 patients randomized between September 2011 and January 2014, 85 were assigned to epoetin- $\alpha$ and 45 to placebo. Baseline patient clinical characteristics were well balanced. The median age was 75 years, and $54.6 \%$ of patients were men (Table 1 and Table S3). Overall, 50\% of patients had an ECOG score of 1.

After 24 weeks, $24.4 \%$ in the placebo group and $17.6 \%$ in the epoetin- $\alpha$ group had discontinued treatment (Fig. 1). The most common reasons for discontinuation were AEs (in $7.1 \%$ of the patients in the epoetin- $\alpha$ group vs $13.3 \%$ of
Table 1 Baseline patient characteristics

\begin{tabular}{llll}
\hline Baseline characteristics & $\begin{array}{l}\text { Placebo } \\
n=45\end{array}$ & $\begin{array}{l}\text { Epoetin- } \alpha \\
n=85\end{array}$ & $\begin{array}{l}\text { Total } \\
N=130\end{array}$ \\
\hline Age (years), median & 75 & 85 & 75 \\
$\quad$ Range (years) & $36-87$ & $40-94$ & $36-94$ \\
Sex & & & \\
$\quad$ Male & $25(55.6 \%)$ & $46(54.1 \%)$ & $71(54.6 \%)$ \\
Female & $20(44.4 \%)$ & $39(45.9 \%)$ & $59(45.4 \%)$ \\
Body mass index (kg/m²) & $n=45$ & $n=84$ & $N=129$ \\
Mean (SD) & 25.94 & 27.58 & 27.01 \\
& $(4.486)$ & $(4.550)$ & $(4.578)$ \\
Median (range) & 25.97 & 27.13 & 26.67 \\
& $(16.1-36.3)$ & $(18.2-40.5)$ & $(16.1-40.5)$ \\
Hemoglobin (g/dL) & & & \\
Mean (SD) & $9(0.848)$ & $9(0.939)$ & \\
Median (range) & 9 & 9 & \\
& $(6.9-10.5)$ & $(6.8-11.0)$ &
\end{tabular}

Transfusions in 8 weeks prior to baseline visit

Patients with

transfusions (\%)

$22(48.9 \%) 44(51.8 \%)$

No. of transfusion events $\quad 36 \quad 75$

prior to baseline

Total RBC units prior to visit

$\mathrm{RBC}$ units required per patient receiving transfusions

MDS subtype according to WHO classification

RA

RARS

RCMD

RCMD-RS

RAEB-1

RAEB-2

MDS-U

5q-

AML

Not available

MDS subtype according to

FAB classification ${ }^{\mathrm{a}}$

\section{RA}

\section{RARS}

RAEB

RAEB-t

CMML

AML

Not available

IPSS risk category ${ }^{\mathrm{b}}$

Low

Intermediate-1 (0.5-1.0)
$53 \quad 114$

$2.4 \quad 2.6$

$n=44 \quad n=82 \quad N=126$

$11(24.4 \%) 7(8.2 \%) \quad 18(13.8 \%)$

$2(4.4 \%) \quad 9(10.6 \%) \quad 11(8.5 \%)$

$21(46.7 \%) \quad 36(42.4 \%) \quad 57(43.8 \%)$

$5(11.1 \%) \quad 12(14.1 \%) \quad 17(13.1 \%)$

$1(2.2 \%) \quad 10(11.8 \%) \quad 11(8.5 \%)$

$0 \quad 1(1.2 \%) \quad 1(0.8 \%)$

$0 \quad 1(1.2 \%) \quad 1(0.8 \%)$

$3(6.7 \%) \quad 2(2.4 \%) \quad 5(3.8 \%)$

$0 \quad 0 \quad 0$

$1(2.2 \%) \quad 4(4.7 \%) \quad 5(3.8 \%)$

$n=44 \quad n=82 \quad N=126$

$35(77.8 \%) \quad 46(54.1 \%) \quad 81(62.3 \%)$

$7(15.6 \%) \quad 21(24.7 \%) \quad 28(21.5 \%)$

$1(2.2 \%) \quad 11(12.9 \%) \quad 12(9.2 \%)$

$0 \quad 0 \quad 0$

$1(2.2 \%) \quad 4(4.7 \%) \quad 5(3.8 \%)$

$0 \quad 0 \quad 0$

$0 \quad 0 \quad 0$

$n=45 \quad n=85 \quad N=130$

$23(51.1 \%) \quad 35(41.2 \%) \quad 58(44.6 \%)$

$22(48.9 \%) \quad 49(57.6 \%) \quad 71(54.6 \%)$ 
Table 1 (continued)

\begin{tabular}{llll}
\hline Baseline characteristics & $\begin{array}{l}\text { Placebo } \\
n=45\end{array}$ & $\begin{array}{l}\text { Epoetin- } \alpha \\
n=85\end{array}$ & $\begin{array}{l}\text { Total } \\
N=130\end{array}$ \\
\hline Intermediate-2 (1.5-2.0) & 0 & 0 & 0 \\
High ( $\geq 2.5)$ & 0 & 0 & 0 \\
Missing & 0 & $1(1.2 \%)$ & $1(0.8 \%)$ \\
$P$ value & & 0.355 & \\
ECOG score & $n=45$ & $n=85$ & $N=130$ \\
0-fully active & $20(44.4 \%)$ & $35(41.2 \%)$ & $55(42.3 \%)$ \\
1-restricted but ambulatory & $23(51.1 \%)$ & $42(49.4 \%)$ & $65(50.0 \%)$ \\
2-ambulatory & $2(4.4 \%)$ & $8(9.4 \%)$ & $10(7.7 \%)$ \\
3-capable but confined to & 0 & 0 & 0 \\
bed/chair & & 0 & 0 \\
4-completely disabled & 0 & 0 & \\
\hline
\end{tabular}

$5 q$ - myelodysplastic syndromes associated with isolated $\operatorname{del}(5 \mathrm{q})$, $A M L$ acute myeloid leukemia, $C M M L$ chronic myelomonocytic leukemia, FAB French-American-British, IPSS International Prognostic Scoring System, ECOG Eastern Cooperative Oncology Group, $M D S$ myelodysplastic syndromes, $M D S-U$ myelodysplastic syndrome, unclassified, $R A$ refractory anemia, $R A R S$ refractory anemia with ringed sideroblasts, $R A E B$ refractory anemia with excess blasts, $R A E B$ - $t$ refractory anemia with excess blasts in transformation, $R B C$ red blood cells, $R C M D$ refractory cytopenia with multilineage dysplasia, $R C M D-R S$ refractory cytopenia with multilineage dysplasia with ringed sideroblasts, $S D$ standard deviation, WHO World Health Organization

${ }^{a}$ According to FAB, CMML patients were marked as MDS subtype not available in the WHO classification

${ }^{\mathrm{b}}$ One patient was missing the IPSS category at screening. The $p$ value for treatment group differences are based on the Fisher exact test, twosided

those in the placebo group) and consent withdrawal (in 4.7 vs $6.7 \%$ ) (Table S4).

Thirty-nine patients in the epoetin- $\alpha$ group and one patient in the placebo group entered the 24-week extension phase. The most common reasons for treatment discontinuation at any time during the 24-week extension phase were no response to treatment and AEs (Table S4).

The median weekly dose delivered was $730.4 \mathrm{IU} / \mathrm{kg}$ (range: $343-946$ ) in the epoetin- $\alpha$ vs $850.0 \mathrm{IU} / \mathrm{kg}$ (range: $404-910)$ in the placebo groups. The epoetin- $\alpha$ dose was decreased in $54.1 \%$ receiving the drug versus $20.0 \%$ in those receiving placebo. The mean treatment duration for the epoetin- $\alpha$ group was 30.9 (standard deviation (SD) 14.04) weeks and 21.3 (SD 6.38) weeks for the placebo group (mITT).

\section{Efficacy results}

\section{ER based on strict IWG 2006 response criteria}

The ER was $31.8 \%$ for the epoetin- $\alpha$ group vs $4.4 \%$ for the placebo group, $(P<0.001 ;$ mITT $)$ Table 2$)$. All responders had a serum erythropoietin level of $<200 \mathrm{mU} /$ $\mathrm{mL}$ at baseline. In patients with no transfusion need, ER was $50 \%$ for epoetin- $\alpha$ vs $4.8 \%$ for placebo. In IPSS lowrisk patients, ER was $45.7 \%$ in the epoetin- $\alpha$ vs $8.7 \%$ in the placebo group; in IPSS intermediate-1 20.4 vs $0 \%$, respectively.

\section{ER based on the modified-IWG-2006 response criteria}

Difficulties in interpretation of IWG-2006 criteria occurred (Table S5). First, patients who transiently discontinued epoetin- $\alpha$ due to $\mathrm{Hb}>12 \mathrm{~g} / \mathrm{dL}$ or received a dose reduction following an increase of $>2 \mathrm{~g} / \mathrm{dL}$ in $\mathrm{Hb}$ over any 4-week period often did not meet IWG-2006 criteria, as their response was $<8$ weeks (due to drug discontinuation/dose reduction). Also, because transfused patients had, as per inclusion criteria, a RBC rate below 4 units/8 weeks, IWG2006 criteria required both RBC-transfusion independence and an increase in $\mathrm{Hb}$ level by $\geq 1.5 \mathrm{~g} / \mathrm{dL}$. In addition, baseline $\mathrm{Hb}$ level is defined in IWG-2006 criteria as "average of $\geq 2$ measurements (not influenced by transfusions), 1 week apart". However, in a patient with lowtransfusion requirement (e.g., every 6 weeks), baseline $\mathrm{Hb}$ levels are not the same in the 2 weeks before and the 2 weeks after transfusions. Also, some epoetin- $\alpha$ dose adjustments were based on local $\mathrm{Hb}$ levels (frequently measured with a portable photometer), which sometimes differed from $\mathrm{Hb}$ levels measured at the centralized laboratory. Finally, the baseline RBC-transfusion rate evaluated during the prior 8 weeks often did not reflect the actual long-term RBC-transfusion rate, which was more accurately captured by analyzing the prior 16 weeks rate.

Taking into account these considerations, the RRC blindly reviewed all cases, based on modified IWG 2006 response assessment. Using these criteria, the proportion of ER in the first 24 weeks was $45.9 \%$ in the epoetin- $\alpha$ treatment group vs $4.4 \%$ in the placebo group $(P<0.001)$.

\section{Other outcomes}

Of the 27 responders, five patients discontinued treatment before week 48 while still in response (median duration 25 weeks, range 13-38). Nine patients were still responding at study end with a median duration of 40 weeks (range 24-46). The remaining 13 patients had relapsed while still on treatment, after a median of 19 weeks (range 8-44). Thus, the mean response duration in responders was 27.5 weeks, while the estimated median Kaplan-Meier estimated duration of response was 44 weeks.

Figure 2 shows the time-to-first-RBC-transfusion between the treatment groups (Kaplan-Meier; mITT). There 


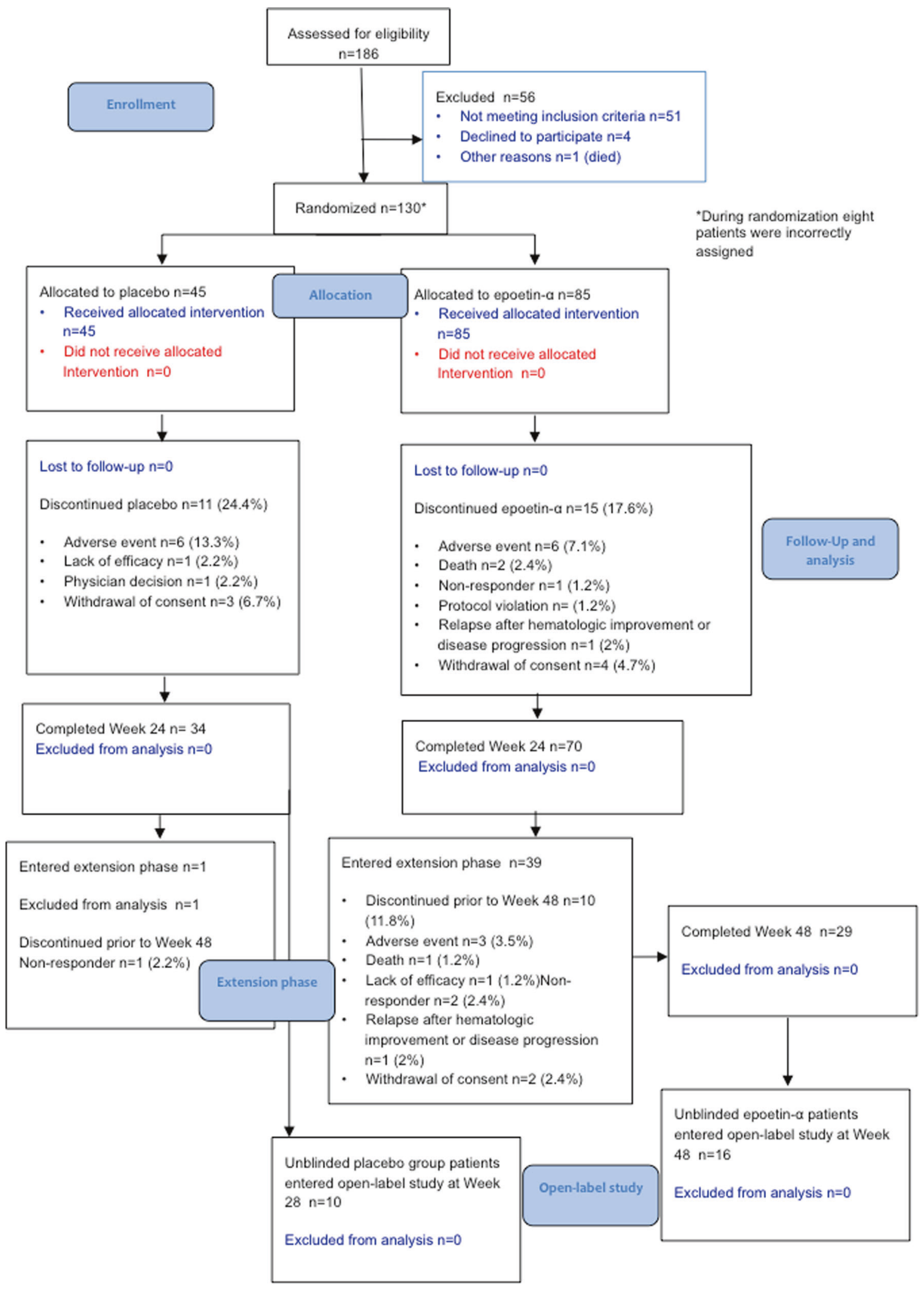

Fig. 1 CONSORT flow diagram 
Table 2 Erythroid response at any time during the first 24 weeks (mITT and PP analyses)

\begin{tabular}{|c|c|c|c|c|}
\hline \multirow[t]{2}{*}{ ER } & \multicolumn{2}{|c|}{ miTT analysis } & \multicolumn{2}{|l|}{ PP analysis } \\
\hline & $\begin{array}{l}\text { Placebo } \\
n=45\end{array}$ & $\begin{array}{l}\text { Epoetin- } \alpha \\
n=85\end{array}$ & $\begin{array}{l}\text { Placebo } \\
n=21\end{array}$ & $\begin{array}{l}\text { Epoetin- } \alpha \\
n=32\end{array}$ \\
\hline $\begin{array}{l}\text { Patients with erythroid response }{ }^{\mathrm{a}} \text { at any time during the first } 24 \text { weeks of the study } \\
\quad P \text { value }^{\mathrm{b}}\end{array}$ & $2(4.4 \%)$ & $\begin{array}{l}27(31.8 \%) \\
<0.001\end{array}$ & 0 & $\begin{array}{l}11(34.4 \%) \\
0.002\end{array}$ \\
\hline \multicolumn{5}{|l|}{ Patients with erythroid response by stratification group } \\
\hline No transfusion and serum erythropoietin level less than $200 \mathrm{mU} / \mathrm{mL}^{\mathrm{c}}$ & $1(4.8 \%)$ & $20(50.0 \%)$ & 0 & $8(66.7 \%)$ \\
\hline Transfusion and serum erythropoietin level less than $200 \mathrm{mU} / \mathrm{mL}^{\mathrm{c}}$ & $1(5.6 \%)$ & $7(22.6 \%)$ & 0 & $3(25.0 \%)$ \\
\hline No transfusion and serum erythropoietin level at least $200 \mathrm{mU} / \mathrm{mL}$ & 0 & 0 & 0 & 0 \\
\hline Transfusion and serum erythropoietin level at least $200 \mathrm{mU} / \mathrm{mL}$ & 0 & 0 & 0 & 0 \\
\hline$P$ value $^{\mathrm{d}}$ & & $<0.001$ & & 0.001 \\
\hline \multicolumn{5}{|l|}{ Patients with erythroid response by IPSS risk category } \\
\hline Low $=0^{\mathrm{e}}$ & $2(8.7 \%)$ & $16(45.7 \%)$ & 0 & $7(58.3 \%)$ \\
\hline Intermediate- $1=0.5-1.0^{\mathrm{e}}$ & 0 & $10(20.4 \%)$ & 0 & $4(20.0 \%)$ \\
\hline Intermediate- $2=1.5-2.0$ & 0 & 0 & 0 & 0 \\
\hline High $=\geq 2.5$ & 0 & 0 & 0 & 0 \\
\hline No IPSS at screening & 0 & 1 & 0 & 0 \\
\hline$P$ value $^{\mathrm{d}}$ & & $<0.001$ & & 0.001 \\
\hline \multirow{2}{*}{$\begin{array}{l}\text { Percentage of patients with erythroid response at any time during the } \\
\text { first } 24 \text { weeks of study for evaluable patients }{ }^{f}\end{array}$} & $2(4.4 \%)$ & $27(32.9 \%)$ & 0 & $11(34.3 \%)$ \\
\hline & High & & Intermediate & Low \\
\hline \multicolumn{5}{|l|}{ ER according to Nordic Score Classification } \\
\hline Responders & $21(44.7 \%)$ & & $6(16.7 \%)$ & \\
\hline Nonresponders & $26(55.3 \%)$ & & $30(83.3 \%)$ & $1(100 \%)$ \\
\hline MDS subtypes & $R A / R C M D$ & & $R A R S / R C M D-R S$ & \\
\hline \multicolumn{5}{|l|}{ ER according to RA/RCMD and RARS/RCMD-RS MDS subtypes } \\
\hline Responders & $13(30.2 \%)$ & & $8(38.1 \%)$ & \\
\hline Nonresponders & $30(69.8 \%)$ & & $13(61.9 \%)$ & \\
\hline
\end{tabular}

$C M H$ Cochran-Mantel-Haenszel, IPSS International Prognostic Scoring Systems, $I W G$ International Working Group, NR not reported; $R B C$ red blood cell, $R R C$ Response Review Committee

${ }^{a}$ Erythroid response assessed according to the IWG 2006 criteria: Hemoglobin increase by $\geq 1.5 \mathrm{~g} / \mathrm{dL}$ or relevant reduction of RBC units transfused by an absolute number of at least four units every 8 weeks compared with the pretreatment transfusion number in the previous 8 weeks; responses must last at least 8 weeks

${ }^{\mathrm{b}} P$ value for treatment group differences are based on the Fisher exact test, two-sided

cmITT analysis: The CMH $p$-value and percentages are based on the number of patients in that strata: placebo, Strata $1=20$ and Strata $2=19$; epoetin alfa, Strata $1=38$ and Strata $2=33$; PP analysis: placebo, Strata $1=8$ and Strata $2=10$; epoetin alfa, Strata $1=12$ and Strata $2=12$ ${ }^{\mathrm{d}} P$ value for treatment group differences are based on the CMH test, two-sided

${ }^{\mathrm{e}}$ The CMH $P$ value and percentages are based on the number of patients in that IPSS category: placebo, low $0=23$ and intermediate- $1=22$; epoetin- $\alpha$, low $0=35$ and intermediate- $1=49$

${ }^{\mathrm{f}}$ The denominator excludes patients who were determined by the RRC as not evaluable

was a significant difference in time-to-first-transfusion in the epoetin- $\alpha$ group vs placebo group (log-rank test: median 7.0 vs 5.3 weeks, respectively $P=0.046$; hazard ratio [HR] 1.653 (95\% confidence interval [CI] 0.999-2.736). The separation between the two treatment groups began around Week 4: the difference in RBC transfusions occurring after Week 4 was a median 20.3 weeks (95\% CI, 7.7-39.6) in the epoetin- $\alpha$, and 7.1 weeks (95\% CI 6.1-9.6) in the placebo groups $(P=0.007)$ (Fig. 3).
Between baseline and Week 24, 36 (42.4\%) patients in the epoetin- $\alpha$ group received 163 transfusions (total RBC units $=266$; units per patients $=7.4)$; and $26(57.8 \%)$ patients in the placebo group received 125 transfusions (total $\mathrm{RBC}$ units $=196$; units per subject $=7.5$ ).

At Week 24, the mean increase from baseline in the $\mathrm{Hb}$ levels in the epoetin- $\alpha$ group was $1.04 \mathrm{~g} / \mathrm{dL}$ and the mean decrease in the $\mathrm{Hb}$ levels in the placebo group was $0.07 \mathrm{~g} / \mathrm{dL}$ (Table S7). 


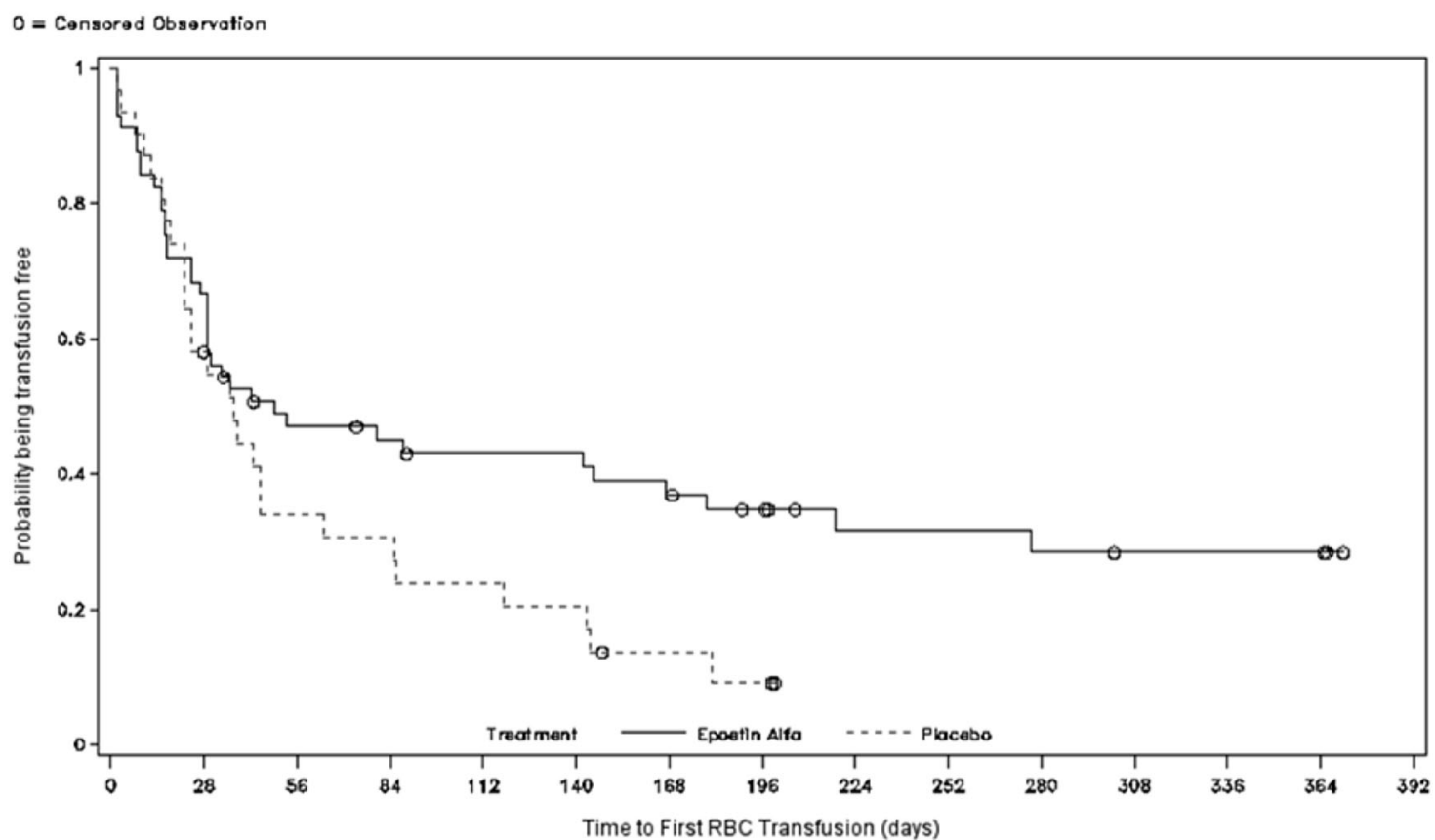

Fig. 2 Time-to-first-red blood cell (RBC)-transfusions (mITT)

\section{QoL}

There were no significant differences in QoL between the epoetin- $\alpha$ group and the placebo at any time point. QoL at Week 24 was significantly different between the responders in the epoetin- $\alpha$ group and the placebo group (EQ-5D index score $P=0.034$ ).

\section{Safety results}

During the 24 weeks of the randomized study (Tables 3 and 4), more patients in the placebo group (88.9\%) reported one or more TEAE compared with the epoetin- $\alpha$ group (77.6\%). At least one TEAE leading to permanent discontinuation of study treatment was reported in $10.6 \%$ of patients in the epoetin- $\alpha$ group and $13.3 \%$ of patients in the placebo group (Table 5). Similar numbers of patients reported at least one TEAE of toxicity grade 3 or grade 4 in the epoetin- $\alpha$ and placebo groups (25.9 vs $26.7 \%$ ).

Treatment-emergent severe adverse events (SAE) were reported by $25.9 \%$ and $17.8 \%$ of patients in the epoetin- $\alpha$ and placebo groups, respectively. Two treatment-emergent SAEs in the epoetin- $\alpha$ group were considered related to study drug by the investigator: thromboembolism (distal deep venous thrombosis, during the first 24 weeks of treatment) and in one patient the anti-erythropoietin antibody testing (after 24 weeks of treatment) was positive during the routine study safety assessment, which led to permanent discontinuation of the study drug. There were no signs of pure red cell aplasia in the patient's bone marrow and serum erythropoietin remained detectable and reticulocytes were normal at the last available measurement.

No SAE reported in the placebo group was considered by the investigator to be related to the study agent.

AEs that occurred at a frequency of $2 \%$ or more in the epoetin- $\alpha$ group or the placebo group were asthenia (14.1 vs $11.1 \%$ ), fatigue (9.4 vs $2.2 \%$ ), nasopharyngitis (7.1 vs $4.4 \%$ ), diarrhea and dyspnea (9.4 vs $2.2 \%$ ), constipation (7.1\% vs 0 ), and pruritus ( $5.9 \%$ vs 0 ).

Thrombovascular events were reported in four patients in the epoetin- $\alpha$ group and none of the patients in the placebo group. Three of the events were confirmed as ischemic stroke, embolism, and phlebitis, and the study investigator considered one embolism to be related to the study agent. Two patients had significant risk factors for thrombovascular events including a medical history or ischemic stroke, atrial fibrillation, congestive heart failure, and superficial thrombophlebitis. No further thrombovascular events were reported in the study after Week 24.

Also, during the first 24 weeks, 11 patients in the epoetin- $\alpha$ group (12.9\%), and 4 patients in the placebo group $(8.9 \%)$ experienced disease progression, including 53 [3.5\%] AML progressions in the epoetin- $\alpha$ group and 2 [4.4\%] in the placebo group. All progressions to AML occurred prior to or at Week 24. After Week 24, three additional patients in the epoetin- $\alpha$ group experienced disease progression (one at Week 44 and two at Week 48) (Table S6). 


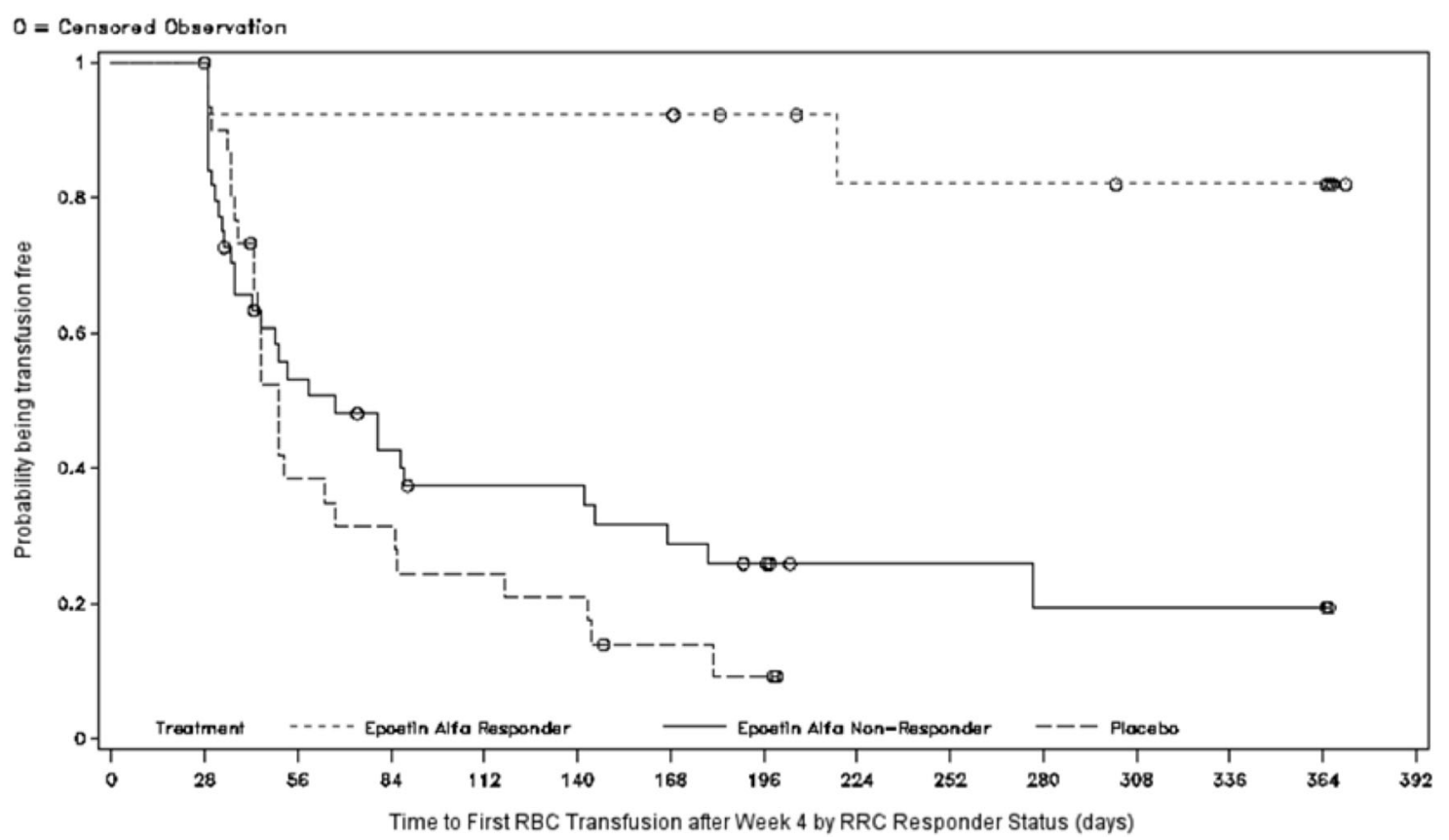

Fig. 3 Time-to-first-red blood cell (RBC)-transfusions after week 4 by RRC responder status (mITT)

Five deaths occurred due to TEAE with onset during the first 24 weeks of the study: four in the epoetin- $\alpha$ group (due to AML, sudden death, cachexia, and renal failure) and one in the placebo group (due to AML). None of the deaths was considered by the investigators to be related to study agent.

\section{Open-label access study: efficacy and safety}

Twenty-six patients enrolled in the open-label access study (Table S8), including 10 non-responders in the placebo group after week 24 , (7 of whom responded to treatment), and 16 patients responders enrolled after 48 weeks to continue treatment (13 did not relapse) (Table S9).

\section{Discussion}

This is the first placebo-controlled, randomized study assessing epoetin- $\alpha$ (without possible addition of G-CSF) in anemia associated with IPSS low- or intermediate-1-risk MDS. Epoetin- $\alpha$ significantly induced and sustained ER (assessed using IWG-2006 criteria), significantly reduced the RBC transfusion requirements, and prolonged the timeto-first-RBC-transfusion.

ER with epoetin- $\alpha$ was $31.8 \%$ strictly applying IWG2006 criteria, i.e., lower than ER generally reported in phase II trials with epoetin- $\alpha$ at similar dosing schedules in lowand intermediate-1-risk MDS patients [13-17]. In a study by Greenberg et al. also applying strictly IWG 2006 criteria, the ER rate with erythropoietin alone was $34 \%$ [13]. On the other hand, in our study, the ER increased to $45.9 \%$ after blindly reviewing responses and adjusting response criteria. Application of IWG-2006 criteria was affected by patients who had to transiently discontinue epoetin- $\alpha$ due to a rapid rise in $\mathrm{Hb}$ level, and therefore, often had responses shorter than 8 weeks (due to drug discontinuation). Additionally, because only moderately transfused patients could be included, not only RBC transfusion independence, but also an increase in $\mathrm{Hb}$ level $>1.5 \mathrm{~g} / \mathrm{dL}$ was required, raising the problem of what baseline $\mathrm{Hb}$ level should be chosen in regularly transfused patients. Other difficulties were the differences in values recorded when $\mathrm{Hb}$ levels were assessed at local centers compared with centralized assessments. For those reasons, a RRC blindly reviewed all cases, based on modifications of IWG-2006 criteria that took into account drug discontinuations due to "over" response, choosing a pre-transfusion baseline level in transfusion dependent patients, and relying only on a centralized $\mathrm{Hb}$ level in case of discrepancies with local $\mathrm{Hb}$ level.

After this review, the ER increased from 31.8 to $45.9 \%$ in the epoetin- $\alpha$ group and remained at $4.4 \%$ in the placebo group. Similar increases in ER after review of IWG 2006 criteria were observed in a recent study of darbepoetin [18]. The results of the open-label access study further support this interpretation, as patients who began treatment with epoetin- $\alpha$ during this phase of the study, had an ER rate of $50 \%$ using IWG-2006 criteria.

In this study, ER was not significantly different in the RARS/RCMD-RS vs RA/RCMD MDS subtypes (38.1 vs 
Table 3 Treatment-emergent AEs that occurred in the first 24 weeks in $\geq 5 \%$ of patients (safety analysis - treatment phase only)

\begin{tabular}{lll}
\hline & $\begin{array}{l}\text { Placebo } \\
n=45\end{array}$ & $\begin{array}{l}\text { Epoetin- } \alpha \\
n=85\end{array}$ \\
\hline General disorders & $17(37.8 \%)$ & $31(36.5 \%)$ \\
$\quad$ Asthenia & $5(11.1 \%)$ & $12(14.1 \%)$ \\
$\quad$ Fatigue & $3(6.7 \%)$ & $8(9.4 \%)$ \\
$\quad$ Pyrexia & $5(11.1 \%)$ & $7(8.2 \%)$ \\
$\quad$ Edema peripheral & $5(11.1 \%)$ & $3(3.5 \%)$ \\
Infections and infestations & $11(24.4 \%)$ & $24(28.2 \%)$ \\
$\quad$ Nasopharyngitis & $2(4.4 \%)$ & $6(7.1 \%)$ \\
Gastrointestinal disorders & $8(17.8 \%)$ & $24(28.2 \%)$ \\
$\quad$ Diarrhea & $1(2.2 \%)$ & $8(9.4 \%)$ \\
$\quad$ Constipation & 0 & $6(7.1 \%)$ \\
Metabolism and nutrition disorders & $4(8.9 \%)$ & $15(17.6 \%)$ \\
Respiratory, thoracic and mediastinal & $4(8.9 \%)$ & $13(15.3 \%)$ \\
disorders & & $8(9.4 \%)$ \\
$\quad$ Dyspnea & $1(2.2 \%)$ & $12(14.1 \%)$ \\
Skin and subcutaneous tissue disorders & $4(8.9 \%)$ & $5(5.9 \%)$ \\
$\quad$ Pruritus & 0 & $11(12.9 \%)$ \\
Musculoskeletal and connective tissue \\
disorders & $11(24.4 \%)$ & \\
$\quad$ Back pain & $3(6.7 \%)$ & $1(1.2 \%)$ \\
Investigations & $7(15.6 \%)$ & $10(11.8 \%)$ \\
Vascular disorders & $4(8.9 \%)$ & $10(11.8 \%)$ \\
Blood and lymphatic system disorders & $7(15.6 \%)$ & $9(10.6 \%)$ \\
$\quad$ Anemia & $5(11.1 \%)$ & $5(5.9 \%)$ \\
Injury, poisoning and procedural & $5(11.1 \%)$ & $8(9.4 \%)$ \\
complications & $3(6.7 \%)$ & $6(7.1 \%)$ \\
Neoplasms benign, malignant and & $7(15.6 \%)$ & $6(7.1 \%)$ \\
unspecified (including cysts and & & \\
Cardiac disorders & & \\
\hline
\end{tabular}

$30.2 \%$ ). Our results were also influenced by Nordic Score prognostic factors [19], based on baseline erythropoietin level and $\mathrm{RBC}$ transfusion requirement. However, the response rates were lower in our study than those reported by HellströmLindberg et al. (e.g., High Nordic Score: 44.7 vs 74\%).

The mean duration of response was 27.5 weeks, and the Kaplan-Meier analysis estimated the median duration of response to be 44 weeks, i.e., less than median responses of 20-24 months usually reported in the literature [13-17]. However, this endpoint was difficult to assess in the present study since many patients discontinued treatment while still responding (including patients deemed non responders per strict IWG 2006 criteria).

The safety findings were consistent with the known profile of epoetin- $\alpha[4,13-15,20-22]$, or were related to patients' underlying health conditions.
Table 4 Treatment-emergent adverse events of toxicity grade 3 or 4 that occurred in the first 24 weeks of the study (safety analysistreatment phase only)

\begin{tabular}{|c|c|c|}
\hline & Placebo & Epoetin- $\alpha$ \\
\hline Infections and infestations & $2(4.4 \%)$ & $5(5.9 \%)$ \\
\hline Pneumonia & $2(4.4 \%)$ & $1(1.2 \%)$ \\
\hline Sinusitis & 0 & $1(1.2 \%)$ \\
\hline Soft tissue infection & 0 & $1(1.2 \%)$ \\
\hline Tooth abscess & 0 & $1(1.2 \%)$ \\
\hline Urosepsis & 0 & $1(1.2 \%)$ \\
\hline Blood and lymphatic system disorders & $\begin{array}{l}2(4.4 \%) \\
1(2.2 \%)\end{array}$ & $1(1.2 \%)$ \\
\hline Anemia & $1(2.2 \%)$ & $1(1.2 \%)$ \\
\hline Thrombocytopenia & $1(2.2 \%)$ & $1(1.2 \%)$ \\
\hline Neutropenia & 0 & $1(1.2 \%)$ \\
\hline Gastrointestinal disorders & $1(2.2 \%)$ & $3(3.5 \%)$ \\
\hline Abdominal pain & 0 & $1(1.2 \%)$ \\
\hline Diarrhea & 0 & $1(1.2 \%)$ \\
\hline Gastritis & 0 & $1(1.2 \%)$ \\
\hline Ileitis & 0 & $1(1.2 \%)$ \\
\hline Esophagitis & 0 & $1(1.2 \%)$ \\
\hline Vomiting & 0 & $1(1.2 \%)$ \\
\hline Toothache & $1(2.2 \%)$ & 0 \\
\hline Vascular disorders & $1(2.2 \%)$ & $2(2.4 \%)$ \\
\hline Embolism & 0 & $1(1.2 \%)$ \\
\hline Systolic hypertension & 0 & $1(1.2 \%)$ \\
\hline Aortic dissection & $1(1.2 \%)$ & 0 \\
\hline $\begin{array}{l}\text { Musculoskeletal and connective tissue } \\
\text { disorders }\end{array}$ & 0 & $2(2.4 \%)$ \\
\hline Back pain & 0 & $1(1.2 \%)$ \\
\hline Pain in extremity & 0 & $1(1.2 \%)$ \\
\hline Investigations & $4(8.9 \%)$ & $1(1.2 \%)$ \\
\hline Blood pressure increased & 0 & $1(1.2 \%)$ \\
\hline Serum ferritin increased & $2(4.4 \%)$ & 0 \\
\hline Hemoglobin decreased & $1(2.2 \%)$ & 0 \\
\hline Lymphocyte count decreased & $1(2.2 \%)$ & 0 \\
\hline Neutrophil count decreased & $1(2.2 \%)$ & 0 \\
\hline White blood cell count decreased & $1(2.2 \%)$ & 0 \\
\hline $\begin{array}{l}\text { Injury, poisoning and procedural } \\
\text { complications }\end{array}$ & 0 & $1(1.2 \%)$ \\
\hline Traumatic brain injury & 0 & $1(1.2 \%)$ \\
\hline Metabolism and nutrition disorders & 0 & $1(1.2 \%)$ \\
\hline Diabetes mellitus & 0 & $1(1.2 \%)$ \\
\hline $\begin{array}{l}\text { General disorders and administration site } \\
\text { conditions }\end{array}$ & $2(4.4 \%)$ & 0 \\
\hline Disease progression & $1(2.2 \%)$ & 0 \\
\hline Pyrexia & $1(2.2 \%)$ & 0 \\
\hline Cardiac disorders & $1(2.2 \%)$ & 0 \\
\hline Arrhythmia & $1(2.2 \%)$ & 0 \\
\hline Psychiatric disorders & $1(2.2 \%)$ & 0 \\
\hline Depression & $1(2.2 \%)$ & 0 \\
\hline
\end{tabular}


Table 5 Summary of key safety findings for the first 24 weeks and for the entire study duration (safety analysis set)

\begin{tabular}{|c|c|c|c|c|}
\hline & \multicolumn{2}{|c|}{ First 24 weeks } & \multicolumn{2}{|l|}{ Entire study ${ }^{\mathrm{a}}$} \\
\hline & Placebo & Epoetin- $\alpha$ & Placebo & Epoetin- $\alpha$ \\
\hline Numbers & 45 & 85 & 24 & 85 \\
\hline At least 1 treatment-emergent $\mathrm{AE}$ & $40(88.9 \%)$ & $66(77.6 \%)$ & $41(91.1 \%)$ & $73(85.9 \%)$ \\
\hline At least 1 treatment-emergent serious $\mathrm{AE}$ & $8(17.8 \%)$ & $22(25.9 \%)$ & $10(22.2 \%)$ & $35(41.2 \%)$ \\
\hline At least 1 treatment-emergent Grade 3 or $4 \mathrm{AE}$ & $12(26.7 \%)$ & $22(25.9 \%)$ & $15(33.3 \%)$ & $32(37.6 \%)$ \\
\hline $\begin{array}{l}\text { At least } 1 \text { treatment-emergent } \mathrm{AE} \text { leading to study } \\
\text { discontinuation }\end{array}$ & $6(13.3 \%)$ & $9(10.6 \%)$ & $6(13.3 \%)$ & $15(17.6 \%)$ \\
\hline Deaths & $1(2.2 \%)$ & $4(4.7 \%)$ & $1(2.2 \%)$ & $7(8.2 \%)$ \\
\hline At least 1 thrombotic vascular event & 0 & $4(4.7 \%)$ & 0 & $4(4.7 \%)$ \\
\hline Disease progression (including progression to AML) & $4(8.9 \%)$ & $11(12.9 \%)$ & $4(8.9 \%)$ & $14(16.5 \%)$ \\
\hline Progression to AML & $2(4.4 \%)$ & $3(3.5 \%)$ & $2(4.4 \%)$ & $3(3.5 \%)$ \\
\hline
\end{tabular}

$A M L$ acute myeloid leukemia

${ }^{a}$ Includes all data from baseline through Week 52 (i.e., end-of-study visit after end of treatment extension phase [Week 48]) for patients who entered the treatment extension phase. For patients who did not enter the treatment extension phase, an end of study visit that included safety evaluations was performed at Week 28 (i.e., 4 weeks after last dose at Week 24); all data after Week 24 through Week 28 for these patients are included in the entire study period data set

This study supports the efficacy and safety of epoetin- $\alpha$ in patients with anemia associated with low-risk MDS. Based on these results, the risk-benefit profile of epoetin- $\alpha$ in the treatment of anemia in patients with low-risk MDS is positive. As a result of this study, epoetin- $\alpha$ has been approved by the French ANSM [23, 24].

Finally, IWG-2006 criteria were difficult to apply, as previously experienced in the MDS 005 study of lenalidomide in non-deletion-5q low-risk MDS [23]. IWG criteria for response assessment may have to be modified to be applicable to clinical study design. Amendments to IWG2006 criteria could include separating RBC transfusion dependent patients into those with low and high RBCtransfusion dependence, defining transfusion dependence over the previous 16 weeks (rather than eight weeks), better defining timing of "baseline $\mathrm{Hb}$ level" and taking into account treatment discontinuation due to "over" response, defining a tolerable period (days) of oscillation of $\mathrm{Hb}$ with subsequent return to previous levels that does not impact on overall response, and the intervals of measurement of $\mathrm{Hb}$ (weekly/biweekly) during treatment.

Acknowledgements Safety monitoring committee: Alan Burnett, Herman Nilsson-Ehle, Santiago Bonanad, Helen Papadaki, Geert Molenberghs; Annette Molhuizen and inVentive Health; Joop Pfeil and Estimate Medical Statistics; Rocket Science Medical Communications.

Funding This work has been sponsored by Janssen-Cilag International NV (NCT01381809).

\section{Compliance with ethical standards}

Conflict of interest Received research funding from Janssen-Cilag: AA, ENO, LG-K. Received research funding and honoraria from
Janssen-Cilag: AS, KSG. Received honoraria from Janssen-Cilag: MHB, UP, and VS. Employees of Janssen: AP, HH, IM, RW. Johnson \& Johnson stockholder: AP. The remaining authors declare no conflict of interest: AG, AR, MAAS, PF, and RS.

Open Access This article is licensed under a Creative Commons Attribution 4.0 International License, which permits use, sharing, adaptation, distribution and reproduction in any medium or format, as long as you give appropriate credit to the original author(s) and the source, provide a link to the Creative Commons license, and indicate if changes were made. The images or other third party material in this article are included in the article's Creative Commons license, unless indicated otherwise in a credit line to the material. If material is not included in the article's Creative Commons license and your intended use is not permitted by statutory regulation or exceeds the permitted use, you will need to obtain permission directly from the copyright holder. To view a copy of this license, visit http://creativecommons. org/licenses/by/4.0/.

\section{References}

1. Steensma DP. Are myelodysplastic syndromes 'cancer'? Unexpected adverse consequences of linguistic ambiguity. Leuk Res. 2006;30:1227-33.

2. Porta MGD, Malcovati L. Clinical relevance of extra-hematologic comorbidity in the management of patients with myelodysplastic syndrome. Haematologica. 2009;94:602-6.

3. Raza A, Reeves JA, Feldman EJ, Dewald GW, Bennett JM, Deeg HJ, et al. Phase 2 study of lenalidomide in transfusion-dependent, low-risk, and intermediate-1 risk myelodysplastic syndromes with karyotypes other than deletion 5q. Blood. 2008;111:86-93.

4. Terpos E, Mougiou A, Kouraklis A, Chatzivassili A, Michalis E, Giannakoulas N, et al. Prolonged administration of erythropoietin increases erythroid response rate in myelodysplastic syndromes: a phase II trial in 281 patients. Br J Haematol. 2002;118:174-80.

5. Giagounidis A, Mufti GJ, Mittelman M, Sanz G, Platzbecker U, Muus P, et al. Outcomes in RBC transfusion-dependent patients with low-/intermediate-1-risk myelodysplastic syndromes with isolated deletion $5 \mathrm{q}$ treated with lenalidomide: a subset analysis from the MDS-004 study. Eur J Haematol. 2014;93:429-38. 
6. Tehranchi R. Impact of growth factors in the regulation of apoptosis in low-risk myelodysplastic syndromes. Med Oncol. 2006;23:37-49.

7. Janssen-Cilag Ltd. Eprex 40,000 IU/ml solution-summary of product characteristics. 2016.

8. Greenberg PL, Stone RM, Al-Kali A, Barta SK, Bejar R, Bennett $\mathrm{JM}$, et al. Myelodysplastic syndromes, version 2.2017, NCCN clinical practice guidelines in oncology. J Natl Compr Canc Netw. 2017;15:60-87.

9. Malcovati L, Hellström-Lindberg E, Bowen D, Adès L, Cermak J, Del Cañizo C, et al. Diagnosis and treatment of primary myelodysplastic syndromes in adults: recommendations from the European LeukemiaNet. Blood . 2013;122:2943-64.

10. Santini V, Alessandrino PE, Angelucci E, Barosi G, Billio A, Di Maio M, et al. Clinical management of myelodysplastic syndromes: update of SIE, SIES, GITMO practice guidelines. Leuk Res. 2010;34:1576-88.

11. Killick SB, Carter C, Culligan D, Dalley C, Das-Gupta E, Drummond $\mathrm{M}$, et al. Guidelines for the diagnosis and management of adult myelodysplastic syndromes. $\mathrm{Br} \mathrm{J}$ Haematol. 2014;164:503-25.

12. Cheson BD, Bennett JM, Kantarjian H, Pinto A, Schiffer CA, Nimer SD, et al. Report of an international working group to standardize response criteria for myelodysplastic syndromes. Blood . 2000;96:3671-4.

13. Greenberg PL, Sun Z, Miller KB, Bennett JM, Tallman MS, Dewald G, et al. Treatment of myelodysplastic syndrome patients with erythropoietin with or without granulocyte colonystimulating factor: results of a prospective randomized phase 3 trial by the Eastern Cooperative Oncology Group (E1996). Blood. 2009;114:2393-2400.

14. Jädersten M, Montgomery SM, Dybedal I, Porwit-MacDonald A, Hellström-Lindberg E. Long-term outcome of treatment of anemia in MDS with erythropoietin and G-CSF. Blood. 2005;106:803-11.

15. Italian Cooperative Study Group for rHuEpo in Myelodysplastic Syndromes, Ferrini PR, Grossi A, Vannucchi AM, Barosi G, Guarnone R, et al. A randomized double-blind placebo-controlled study with subcutaneous recombinant human erythropoietin in patients with low-risk myelodysplastic syndromes. Br J Haematol. 1998;103:1070-4.
16. Mantovani L, Lentini G, Hentschel B, Wickramanayake PD, Loeffler M, Diehl V, et al. Treatment of anaemia in myelodysplastic syndromes with prolonged administration of recombinant human granulocyte colony-stimulating factor and erythropoietin. Br J Haematol. 2000;109:367-75.

17. Spiriti MAA, Latagliata R, Niscola P, Cortelezzi A, Francesconi $\mathrm{M}$, Ferrari $\mathrm{D}$, et al. Impact of a new dosing regimen of epoetin alfa on quality of life and anemia in patients with low-risk myelodysplastic syndrome. Ann Hematol. 2004;84:167-76.

18. Platzbecker U, Symeonidis A, Oliva EN, Goede JS, Delforge M, Mayer J, et al. A phase 3 randomized placebo-controlled trial of darbepoetin alfa in patients with anemia and lower-risk myelodysplastic syndromes. Leukemia. 2017;31:1944-50. https://doi. org/10.1038/leu.2017.192

19. Hellström-Lindberg E, Negrin R, Stein R, Krantz S, Lindberg G, Vardiman J, et al. Erythroid response to treatment with G-CSF plus erythropoietin for the anaemia of patients with myelodysplastic syndromes: proposal for a predictive model. $\mathrm{Br} \mathrm{J}$ Haematol. 1997;99:344-51.

20. Spiriti MAA, Latagliata R, Niscola P, Cortelezzi A, Francesconi $\mathrm{M}$, Ferrari D, et al. Impact of a new dosing regimen of epoetin alfa on quality of life and anemia in patients with low-risk myelodysplastic syndrome. Ann Hematol. 2005;84:167-76.

21. Mitjavila MT, Villeval JL, Cramer P, Henri A, Gasson J, Krystal $\mathrm{G}$, et al. Effects of granulocyte-macrophage colony-stimulating factor and erythropoietin on leukemic erythroid colony formation in human early erythroblastic leukemias. Blood. 1987;70:965-73.

22. Rose EH, Abels RI, Nelson RA, McCullough DM, Lessin L. The use of r-HuEpo in the treatment of anaemia related to myelodysplasia (MDS). Br J Haematol. 1995;89:831-7.

23. Santini V, Almeida A, Giagounidis A, Gröpper S, Jonasova A, Vey N, et al. Randomized phase III study of lenalidomide versus placebo in RBC transfusion-dependent patients with lower-risk non-del(5q) myelodysplastic syndromes and ineligible for or refractory to erythropoiesis-stimulating agents. J Clin Oncol. 2016;34:2988-96.

24. Janssen Press Release. https://www.jnj.com/media-center/pressreleases/eprex-epoetin-alfa-marketing-authorisation-extended-toinclude-treatment-of-symptomatic-anaemia-in-patients-with-lowor-intermediate-1-risk-myelodysplastic-syndromes. Accessed 20 Apr 2017. 